\title{
Imigração e Refúgio no Brasil e os programas especiais de acesso ao ensino superior: levantamentos iniciais dos programas implementados até 2016.
}

\section{RESUMO}

Até 2016, durante a vigência da Lei 6.815/80, o Estatuto do Estrangeiro, foram criados vários programas de acesso ao ensino superior a migrantes e refugiados no Brasil, dos quais onze programas abriram editais de admissão de estudantes. $\mathrm{O}$ Estatuto não garantia acesso à educação como um direito àqueles que estivessem sob a sua tutela, como migrantes, portadores de visto humanitário e em alguma medida, solicitantes de refúgio. O presente trabalho propõe-se a realizar um levantamento inicial dos programas implementados até 2016, avaliar seus critérios de admissibilidade e ressaltar a distribuição territorial dos programas em diferentes regiões do Brasil. Também serão analisados os tipos de seleção propostos: vestibulares especiais, faixa de reserva de vagas e documentação requerida, e critérios avaliados como determinantes à adesão a esses programas considerando a disponibilidade ou não de recursos como documentação, tempo e informação aos postulantes. Contata-se que a diferente abrangência ou limitação conforme o status jurídico dos programas pode ser considerada como um elemento influenciado pela distribuição espacial de migrantes de diferentes categorias jurídicas.

\section{Categorias migratórias e o direito à educação superior: levantamentos iniciais e questões metodológicas}

Migrantes, solicitantes de refúgio, refugiados, apátridas, deslocados internos, "refugee-like situation", portadores de visto humanitário... A lei, os documentos oficiais do Alto Comissariado das Nações Unidas para Refugiados e os trabalhos acadêmicos estão cheios de categorias para definir as pessoas que estão em cada uma dessas condições jurídicas, através de diferentes discursos. Ainda que os status jurídicos não sejam determinantes para compreender as experiências dos sujeitos, eles definem o alcance de seu acesso a direitos, fundados dentro do contexto de um sistema de refúgio através do processo de elegibilidade- momento no qual a situação de ser ou não refugiado é declarada. A chegada de migrantes haitianos e de outras nacionalidades e a entrada das migrações e refúgio como tema de destaque internacional repercutiram com a inserção do Brasil na rota das migrações transnacionais do século XXI (BAENINGER, 2017), compelindo o poder público e suas instituições a serem confrontadas com as limitações no acesso a serviços e políticas públicas para pessoas migrantes. Como referem Magalhães e Waldman (2016:166), um solicitante de refúgio que tenha seu pedido negado não gozará de um conjunto de direitos a que tem acesso

\footnotetext{
${ }^{1}$ Programa de Pós Graduação em Ciências Humanas e Sociais na Universidade Federal do ABC (UFABC).

${ }^{2}$ Professora Visitante
} 
os refugiados "reconhecidos", ainda que as necessidades de ambos sejam muito equivalentes.O acesso à educação como direito não deveria estar sujeito à classificação ou status jurídico reconhecido. Contudo, justamente pela premissa de que o acesso a direitos deve ser universal, tomamos o critério do status jurídico como uma categoria de análise dos programas selecionados.

Nesse sentido, o tratamento dado pelas leis aos diferentes status migratórios foi determinante, visto que a legislação, até meados de 2017, elencava garantias aos refugiados (Lei 9.474/97), que não estavam previstas para migrantes com outros status, como solicitantes de refúgio e pessoas que ingressaram no país através de visto permanente por razões humanitárias, deslocados ambientais, e partilhavam com os demais migrantes a tutela da lei genérica de estrangeiros presente na legislação anterior (Lei 6.815/80) e que regulava grande parte das categorias migratórias. A sanção da nova Lei de Migração (Lei nº 13.445/17) com a previsão de acesso à direitos e políticas públicas poderá em grande medida auxiliar na implementação de direitos, ainda que esses dependam da ação do poder público em promover políticas sociais.

A dificuldade no acesso a direitos segue, portanto, como uma questão pendente de políticas públicas, muitas vezes refletidas pelas desigualdades regionais. Diferentes graus de envolvimento dos entes federativos na questão imigratória também são relevantes, tendo sido observada uma municipalização no tratamento das políticas para migrantes, no caso da cidade de São Paulo, com previsões da política municipal para o tratamento de forma transversal entre migrações e educação ${ }^{3}$. A questão do acesso ao ensino superior é de competência federal, considerando também a autonomia das universidades públicas na criação de programas de acesso e revalidação de diplomas, o que colabora para que diferentes estados desenvolvam programas de forma tão díspar. Ainda que a distribuição territorial de migrantes no Brasil também seja heterogênea, temos que o acesso à educação, sobretudo em nível superior, é essencial porque, quando ausente, limita a integração local e o usufruto de direitos, acesso ao trabalho e cidadania plenas, elementos constatados em pesquisa realizada em todo o território nacional acerca dos desafios enfrentados por migrantes e refugiados (Ministério da Justiça, 2015).

\footnotetext{
${ }^{3}$ A Política Municipal para População Imigrante (Lei 16.478/16 ) da cidade de São Paulo prevê a garantia de acesso, permanência e terminalidade à educação para a população imigrante na rede municipal de ensino, com a flexibilização de documentos e a promoção de interculturalidade nos ambientes de ensino e aprendizagem, inclusive com a inclusão de temáticas ligadas as culturas migrantes nas grades curriculares. A política também possui mecanismos de formação permanente de servidores municipais, com curso ofertado pela Coordenação de Políticas para Migrantes (CPMIg) e Centro de Referência para Migrantes (CRAI), em parceria com a EMASP (Escola Municipal de Administração Pública de São Paulo).
} 
Portanto, o presente trabalho propõe-se a analisar os programas de acesso ao ensino superior criados até 2016 com previsões especiais de acesso para migrantes e refugiados em universidades públicas brasileiras, tendo como marco temporal a vigência da Lei 6.815/80. Foram incluídos na análise instituições federais e estaduais, contudo, existem também institutos federais e instituições da rede privada que oferecem programas similares que, por questões metodológicas, não foram avaliados ${ }^{4}$. Não havia, até o momento, fontes que reunissem informações sobre as universidades públicas que dispõe de programas especiais para imigrantes e refugiados no Brasil, sendo a primeira etapa desse estudo um levantamento das instituições que os oferecem. Após o levantamento, foram consultadas as normativas e resoluções que regem os programas especiais e, quando disponíveis, dados sobre os programas prestados e publicados pelas universidades.

Os programas criados e implementados até 2016 abrangem onze universidades públicas em diferentes regiões do país, tendo sido analisadas as políticas das seguintes instituições: Universidade de Brasília (UNB), Universidade Federal de Juiz de Fora (UFJF), Universidade Estadual de Goiás (UEG), Universidade Federal de São Carlos (UFSCAR), Universidade Federal de Minas Gerais (UFMG), Universidade Federal do Espírito Santo (UFES), Universidade Federal da Integração Latino-Americana (UNILA), Universidade Federal da Fronteira Sul (UFFS), Universidade Federal do Paraná (UFPR), Universidade Federal do Triângulo Mineiro (UFTM) e Universidade Federal de Santa Maria (UFSM). Todos os programas são vigentes e já lançaram editais de seleção. ${ }^{5}$ Dentre os programas avaliados, destacamos diferentes critérios de seleção dos participantes, como a nacionalidade e status jurídicos dos candidatos, formatos variados de processo seletivo, reserva de vagas, políticas de assistência estudantil, dentre outros. Os resultados indicam uma predominância geográfica de programas de acesso nas regiões sul e sudeste, o que insta investigar se ocorre devido a uma maior concentração de migrantes nessas áreas, ou ainda, se contribui para atrair migrantes para essas regiões.

\footnotetext{
${ }^{4}$ Optamos por avaliar apenas os programas de universidades públicas, por permitir traçar paralelos entre os programas ofertados e também por compreender que representam formas governamentais de atender a demanda de acesso a educação. Ademais, avalia-se que a instauração da rede de Cátedras do ACNUR é um elemento relevante na implementação de programas, sendo que os institutos federais não integram sua extensão, ainda que estejam presentes nas universidades privadas que tem programas de acesso (UniSantos, PUC-SP, FGV, Unisinos e UVV).

${ }^{5}$ Entramos em contato com as instituições e agradecemos o auxílio da UNB, UFRGS, UFTM, UFMG e UFES, que disponibilizaram informações sobre seus programas. Informações também foram acessadas de forma direta com a UFSM e a UFABC, pela ligação institucional das autoras. Sobre a UFSCAR, UEG, UFRR, UFPR, UFFS e UNILA foram utilizados os dados publicados pelas instituições.
} 


\section{Programas especiais de acesso ao ensino superior para diferentes status jurídicos}

migrantes no Brasil: dados sobre os programas criados até 2010

$\mathrm{O}$ acesso ao ensino superior assume diferentes configurações dentre os programas elencados para análise, dentre critérios de seleção, reserva de vagas, categorias jurídicas contempladas, previsão de acesso à assistência estudantil e regularidade dos editais. Para fins de exposição didática, organizamos uma lista com os programas existentes, trazendo também alguns em implementação, classificados pelos critérios mencionados de forma a orientar nossa pesquisa. Após, iremos proceder a análise individual dos programas implementados, destacando os aspectos relevantes:

\section{PROGRAMAS CRIADOS E IMPLEMENTADOS ATÉ 2016}

\begin{tabular}{|c|c|c|c|c|}
\hline & Instituição e Unidade Federativa & $\begin{array}{l}\text { Ano de } \\
\text { criação* }\end{array}$ & $\begin{array}{l}\text { Programa de } \\
\text { permanência }^{6}\end{array}$ & Status jurídico contemplado \\
\hline 1. & $\begin{array}{lllll}\begin{array}{l}\text { Universidade } \\
\text { (UFMG/MG) }\end{array} & \text { Federal } & \text { de } & \text { Minas } & \text { Gerais } \\
\end{array}$ & $1998 / 2004$ & GERAL & Refugiados \\
\hline 2. & $\begin{array}{llllll}\begin{array}{l}\text { Universidade } \\
\text { (UFJF/MG) }\end{array} & \text { Federal } & \text { de } & \text { Juiz } & \text { de } & \text { Fora } \\
\end{array}$ & $2003 / 2004$ & GERAL & Refugiados \\
\hline 3. & Universidade de Brasília (UNB/DF) & 2007 & GERAL & Refugiados \\
\hline 4. & \begin{tabular}{lllll|}
$\begin{array}{l}\text { Universidade } \\
\text { (UFSCAR/SP) }\end{array}$ & Federal & de & São & Carlos \\
\end{tabular} & 2008 & GERAL & Refugiados \\
\hline 5. & $\begin{array}{lllll}\begin{array}{l}\text { Universidade } \\
\text { (UFES/ES) }\end{array} & \text { Federal } & \text { do } & \text { Espírito } & \text { Santo } \\
\end{array}$ & 2010 & & Refugiados \\
\hline 6. & Universidade Federal do Paraná (UFPR/PR) & 2014 & GERAL & \begin{tabular}{|l} 
Refugiados e portadores de visto \\
humanitário
\end{tabular} \\
\hline 7. & $\begin{array}{lcccc}\text { Universidade } & \text { Federal } & \text { da } & \text { Fronteira } & \text { Sul } \\
\text { (UFFS/PR, SC, RS) }\end{array}$ & 2013 & GERAL & Haitianos \\
\hline 8. & $\begin{array}{l}\text { Universidade Federal da Integração Latino- } \\
\text { Americana (UNILA/PR) }\end{array}$ & 2014 & SIM & Haitianos \\
\hline 9. & Universidade Estadual de Goiás (UEG/GO) & 2015 & GERAL & \begin{tabular}{|l}
$\begin{array}{l}\text { Refugiados e portadores de } \\
\text { humanitário }\end{array}$ \\
\end{tabular} \\
\hline 10. & $\begin{array}{l}\text { Universidade Federal do Triângulo Mineiro } \\
\text { (UFTM/MG) }\end{array}$ & 2016 & GERAL & Refugiados \\
\hline 11. & $\begin{array}{l}\begin{array}{l}\text { Universidade } \\
\text { (UFSM/RS) }\end{array} \\
\text { Federal de }\end{array}$ & 2016 & SIM & $\begin{array}{|lrr|}\text { Refugiados, portadores de } & \text { visto } \\
\text { humanitário em situação } & \text { de } \\
\text { vulnerabilidade social } & & \\
\end{array}$ \\
\hline 12. & Universidade Federal de Roraima (UFRR/RR) & $2008 * *$ & GERAL & Refugiados \\
\hline 13. & $\begin{array}{l}\text { Universidade Federal do Rio Grande do Sul } \\
\text { UFRGS/RS) }\end{array}$ & $2015 * *$ & GERAL & Refugiados \\
\hline 14. & Universidade Federal do ABC (UFABC/SP) & $2017 * *$ & SIM & Refugiados e solicitantes de refúgio \\
\hline
\end{tabular}

${ }^{6}$ Foram considerados "sim" os programas com previsão de acesso à políticas de permanência previstas nas resoluções que os instituem, considerando que a previsão expressa confere maior segurança jurídica aos candidatos, embora seja facultado o acesso às políticas de permanência universais em todas as instituições, que classificamos como "geral". 
Dentre os programas criados até o momento, destacamos alguns critérios interessantes, como o papel da criação das Cátedras Sérgio Vieira de Mello (CSVM), parceria firmada entre Universidades e o Alto Comissariado das Nações Unidas para Refugiados $(\mathrm{ACNUR})^{7}$. O objetivo das Cátedras é promover o debate sobre refúgio no Brasil, com a implementação de ações como a abertura de disciplinas e o desenvolvimento de atividades de pesquisa em cursos de graduação e pós-graduação sobre os temas de migrações e refúgio, assim como atividades de extensão em integração, como cursos de português para migrantes, fomento ou auxílio e flexibilização da revalidação de diplomas estrangeiros por universidades brasileiras, e ainda, a criação de vagas de acesso a refugiados em cursos de ensino superior em nível de graduação, pós-graduação, tecnólogos, entre outros. Rodrigues (2014) ressalta o papel das Cátedras na formação de uma rede de articulação entre instituições, e destaca a criação do programa de acesso da Universidade Federal de São Carlos (UFSCAR) como referência para a implementação de programas semelhantes em outras universidades, como a Universidade Católica de Santos (Unisantos), a Universidade Federal de Minas Gerais (UFMG) e a Universidade Federal de Juiz de Fora (UFJF).

Outro elemento relevante é a concentração territorial dos programas por regiões: dos onze programas em atividade, cinco estão localizados no sudeste entre Minas Gerais, Espírito Santo e São Paulo e quatro no sul, no Paraná, Santa Cataria e Rio Grande do Sul. A convergência dos programas nessas duas regiões dialoga com os dados sobre distribuição geográfica segundo o ACNUR, que apontam a predominância de refugiados nas regiões sul e sudeste (ACNUR, 2014), o que vai ao encontro, com pequena variação, aos dados do SINCRE (Sistema Nacional de Cadastramento de Registro de Estrangeiros da Polícia Federal), de 2000 a 2014, que indicam prevalência nos estados de São Paulo, Rio de Janeiro, Rio Grande do Sul, Paraná e Minas Gerais (COSTA, 2016:113). Embora São Paulo concentre o maior número de refugiados, seguido pelo Rio de Janeiro, temos que a maioria das vagas disponíveis está em universidades mineiras, sem que haja registros de programas de acesso no Rio.

Quanto aos haitianos, embora os números sejam imprecisos por combinarem diferentes bases de dados, e também sendo importante considerar as diferenças entre o local do pedido da documentação e o de residência, dados do SINCRE indicam que a maior parte dos migrantes haitianos residem em São Paulo, Paraná, Santa Catarina e Rio Grande do Sul respectivamente, sendo observada a "mobilidade espacial entre centros econômicos" na

\footnotetext{
${ }^{7} \mathrm{~A}$ maioria dos programas criados participa das Cátedras. Dentre os implementados, até o momento não são participantes seis universidades: UNB, UFJF, UFMG, UFTM, UFFS e UNILA.
} 
comparação entre os locais de entrada e residência (COSTA, 2016:115). Tal concentração desponta como um elemento que corrobora para que os programas da região sul tenham abrangência também para portadores de visto por razões humanitárias, e não somente para refugiados, o que indica a sintonia das instituições da região com a realidade vivenciada pelos migrantes fora da universidade.

Dando sequência à análise dos programas implementados, agrupamos as universidades conforme os critérios de status jurídico: programas voltados apenas para refugiados, programas que aceitam solicitantes de refúgio e portadores de visto humanitário e programas voltados apenas para haitianos. Dentre os programas existentes há também dois modelos de seleção diferentes: programas que abrem editais de seleção, com a realização de provas, e programas em que o acesso é realizado unicamente através do protocolo de documentos.

\subsection{Programas implementados específicos para refugiados: UFSCAR, UFMG, UNB, UFES, UFJF e UFTM}

A Lei 9.474/1997, o Estatuto dos Refugiados, prevê algumas garantias para refugiados reconhecidos, em seu artigos 43 e 44, como que sua situação seja considerada quando houver necessidade de apresentação de documentos, assim como a facilitação de revalidação e reconhecimento de certificados e diplomas, elementos esses importantes para sua integração local. É sabido também que o acesso a cursos como o PRONATEC são estendidos a refugiados, com a oferta de vagas para cursos técnicos e de português, assim como parcerias firmadas para cursos no SEBRAE (CONARE, 2016), embora esses benefícios não sejam oferecidos a migrantes de outros status jurídicos e solicitantes de refúgio.

Não obstante tais iniciativas e garantias, o acesso ao ensino superior e a revalidação de diplomas está longe de ser um direito plenamente acessado por refugiados no Brasil, na verdade, esse é um dos grandes empecilhos para sua integração à sociedade. A discussão sobre a revalidação de diplomas é árdua, com algumas poucas iniciativas dentro da esfera das migrações regionais no Mercosul $^{8}$ ainda longe de estarem implementadas através de um reconhecimento mais célere de títulos obtidos nos países pertencentes ao bloco. Nesse sentido, para pessoas vindas de outras regiões do mundo, torna-se ainda mais difícil a obtenção da revalidação, tendo surgido iniciativas no sentido de promover o acesso ao mercado de trabalho e ao ensino superior através de processos seletivos especiais em

\footnotetext{
${ }^{8}$ Acordo entre Brasil e países do Mercosul, o Arcu-Sul, Regulamentado pela Decisão CMC n 17/08 é uma parceria para acelerar o processo de revalidação de diplomas, mas beneficia sobretudo brasileiros que tenham cursado graduação no exterior.
} 
universidades. Destacamos os programas existentes até o momento, dentre os já implementados, sem desprestigiar as iniciativas dessas e de outras universidades e instituições para a promoção da revalidação de títulos obtidos no exterior por refugiados ${ }^{9}$.

O primeiro programa de acesso por seleção especial do Brasil é da UFSCAR ${ }^{10}$, criado em 2008. Realizado anualmente desde 2009, conta com processo seletivo específico para pessoas com o status de refugiado reconhecido e garante uma vaga adicional em cada curso de graduação, independente do número de vagas ociosas nos $\operatorname{cursos}^{11}$. As primeiras provas eram aplicadas mediante a elaboração de exame escrito de múltipla escolha, com conteúdos referentes as disciplinas cursadas no ensino secundário brasileiro, além de prova de redação e prova oral em língua portuguesa, com temas conexos à área de conhecimento do curso concorrido. Tal modelo foi modificado em 2013, com elaboração da prova objetiva conforme os conteúdos exigidos no Exame Nacional do Ensino Médio (ENEM) e mantidas a redação e a prova oral (UFSCAR, 2016). Na eventualidade de não haver candidatos suficientes para as vagas ofertadas, a universidade prevê a realização de um processo seletivo simplificado pela aplicação de prova de redação ${ }^{12}$. O programa passou por reformulação ${ }^{13}$, tendo sido apontado como um dos desafios o modo de seleção, inicialmente presencial, o que incorria em uma grande taxa de ausência, observada também no processo seletivo especial para candidatos indígenas, já que para a realização dos exames era necessária a realização das provas em um polo da universidade. Por essa razão, no edital lançado em 2016 foi incluído o ENEM como único modelo de acesso, o que possibilitou uma maior adesão ao último exame, sendo aprovados os candidatos que obtiverem maior nota no ENEM dentre os inscritos para cada curso. A universidade aponta a falta de divulgação como um empecilho no preenchimento de vagas (UFSCAR, 2016:43):

Persiste o desafio de criar condições para ampliar a divulgação junto ao público alvo, ou seja, para uma população equivalente a quase nove mil Refugiados existente atualmente no Brasil, de acordo com as informações oficiais do Comitê Nacional para os Refugiados. As estratégias de divulgação passam pela necessidade de reforçar os contatos com associações, organizações e coletivos que atuam no acolhimento, assistência e mantém vínculo com pessoas em situação de refúgio no Brasil.

\footnotetext{
${ }^{9}$ Destacamos algumas ações recentes do ACNUR em parceria com ONGs e Sociedade Civil, como a Compassiva e a Cáritas, assim como ações das Cátedras para a promoção da revalidação de diplomas. Também há registros de negociações entre a Andifes e o CONARE para ações com esse fim (CONARE, 2016).

${ }^{10} \mathrm{O}$ programa é citado por autores como o mais antigo (RODRIGUES, 2014; BÓGUS, RODRIGUES, 2011), contudo, temos outros casos de programas anteriores de acesso, sem que houvesse a realização de editais de processo seletivo. Esses programas funcionavam apenas com a apresentação de documentos, como no caso da UNB e da UFMG.

${ }^{11}$ Conforme §único, artigo $3^{\circ}$, da Portaria GR n ${ }^{\circ}$ 941/08, de 09 de junho de 2008.

${ }^{12}$ Art. $6^{\circ}$, Edital 004/15.

${ }^{13}$ Inicialmente regulado pela resolução CEPE no 584, de 30/05/2008, que foi revogada pela Resolução ${ }^{\circ} 71$ de 11 de maio de 2015 .
} 
O aumento da procura pela universidade foi relacionado à adesão ao ENEM como modo de seleção, contudo, existem poucos dados acerca do papel das políticas de assistência estudantil para a permanência dos discentes, sendo apenas possível saber que o acesso à assistência é ofertado sem distinção de nacionalidade (UFSCAR, 2016b). Uma vez realizado o processo seletivo, o candidato poderá ter seu resultado considerado por três anos, caso não possa preencher a vaga ${ }^{14}$, contudo, somente poderá selecionar uma opção de curso $^{15}$. A inscrição é realizada pelo correio com aviso de recebimento, o que possibilita participação de candidatos residentes em outras localidades. Dados sobre a origem dos selecionados para o programa indicam um total de 14 ingressantes entre 2009 e 2016, grande parte da África e da América Latina:

\begin{tabular}{|l|l|l|l|l|}
\hline ANO & Inscritos & Ingressos & ORIGEM & CURSO \\
\hline 2009 & 3 & 2 & África & Administração e Medicina \\
\hline 2010 & 4 & 3 & $\begin{array}{l}\text { África, Oriente Médio e } \\
\text { América Latina }\end{array}$ & $\begin{array}{l}\text { Imagem e Som, Engenharia } \\
\text { Civil e Engenharia de Produção }\end{array}$ \\
\hline 2011 & 5 & 2 & América Latina & Medicina e Ciências Sociais \\
\hline 2012 & 2 & 1 & Oriente Médio & Engenharia da Computação \\
\hline 2013 & 5 & 1 & América Latina & Medicina \\
\hline 2014 & 6 & 1 & África & Engenharia Civil \\
\hline 2015 & 12 & 1 & América Latina & Medicina \\
\hline 2016 & 7 & 3 & África e América Latina & $\begin{array}{l}\text { Enfermagem, Engenharia Civil e } \\
\text { Medicina }\end{array}$ \\
\hline TOTAL & $\mathbf{4 4}$ & $\mathbf{1 4}$ & & \\
\hline
\end{tabular}

Fonte: Adaptado de UFSCAR (2016:42-43)

Já consolidado, o programa mais antigo do Brasil é da Universidade Federal de Minas Gerais, que foi criado em 1998, com o primeiro ingresso de estudantes em $1999^{16}$. Até o momento, a UFMG teve trinta e dois ingressantes: vinte e oito angolanos, um camaronês, um colombiano, um guineense e um congolês; dezesseis já estão formados e a procura ocorreu em cursos de todas as áreas do conhecimento ${ }^{17}$. Conforme as normas atuais do programa, as inscrições são realizadas pessoalmente e o acesso se dá unicamente pela via de inscrição e comprovação documental, com a previsão de uma vaga ofertada por curso, facultado aos colegiados de cada curso a destinação do número de vagas e a realização de

\footnotetext{
${ }^{14}$ Conforme redação do $\S 1^{\circ}$, art. $1^{\circ}$, Resolução ${ }^{\circ}$. 71 , de 11 de maio de 2015.

15 Ibid, art. $3^{\circ}$, caput.

${ }^{16}$ Criado mediante a Resolução 03/1998, CEP, substituida pela Resolução no 03/2004, de 19 de agosto de 2004.

${ }^{17}$ Agradecemos as informações prestadas pelo Departamento de Controle e Registro Acadêmico da UFMG em setembro de 2017. Dentre os cursos com procura, foram indicados os seguintes: Administração, Arquitetura e Urbanismo, Artes Visuais, Ciência da Computação, Ciências Biológicas, Ciências Contábeis, Ciências Econômicas, Ciências Sociais, Comunicação Social, Direito, Educação Física, Enfermagem, Engenharia Civil, Engenharia de Controle e Automação, Engenharia Química, elétrica, de Minas, de Produção, Farmácia, Filosofia, Fisioterapia, Fonoaudiologia, Geologia, História , Letras, Medicina, Odontologia, Psicologia e Terapia Ocupacional.
} 
provas específicas ${ }^{18}$. Em 2017, a Clínica de Direitos Humanos do Curso de Direito da UFMG encaminhou um parecer opinando pela reformulação da resolução que norteia o programa, de forma a incluir portadores de visto humanitário na universidade ${ }^{19}$. O processo em curso, aberto para ingresso em 2018 sem a realização de edital, prevê apresentação de documentos e cópias comprobatórias da condição de refugiado, RNE, certificado de conclusão e histórico escolar ou equivalente com parecer de equivalência emitido pela Secretaria Estadual de Educação, sendo admitida também certificação emitida pelo $\operatorname{CONARE}^{20}$.

Seguindo as tendências do programa anterior, outras duas universidades tem previsão de seleção por apresentação de documentos. A primeira é a Universidade de Brasília, com programa criado em $2007^{21}$. O ingresso é direto, mediante requerimento e apresentação de documentos, sem a necessidade de realização de provas $^{22}$ e vem sendo admitidos alunos refugiados na instituição. Também foi criado, em 2010, programa na Universidade Federal do Espírito Santo $^{23}$, com a previsão de uma vaga por curso, além de outras vagas e normas de seleção que ficam a cargo dos colegiados de cursos. A normativa que regulamenta o programa traz a previsão de uma solicitação do MEC para a criação de mecanismos de ingresso a refugiados em cursos de graduação ${ }^{24}$, o que também foi apontado pela UFTM como um motivador para a criação do programa ${ }^{25}$.

Além da UFMG, outras duas universidades no estado de Minas Gerais também tem processos voltados para o acesso a refugiados reconhecidos. O programa da Universidade Federal de Juiz de Fora (UFJF) foi criado em $2003^{26}$, sendo estimado o ingresso de nove refugiados acolhidos no campus, quatro formados um transferido até 2016 (UFJF, 2016). Em 2017, foi aberto processo seletivo com vagas destinadas por cada coordenação dos cursos de graduação após o período de matriculas, portanto em regime suplementar de vagas remanescentes, ainda que as vagas sejam criadas independentemente da existência de vagas

\footnotetext{
${ }^{18}$ Resolução $n^{\circ} .71$, de 11 de maio de 2015 , art. $3^{\circ}$.

${ }^{19}$ Conforme notícia veiculada no site da Clínica de Direitos Humanos da UFMG.

${ }^{20}$ Art. $3^{\circ}, \S 2^{\circ}$, Resolução no 03/2004, de 19 de agosto de 2004.

${ }^{21}$ Criado pela Resolução CEPE n ${ }^{\circ}$ 64/2007, UNB

${ }^{22}$ Foi realizada consulta com a Universidade de Brasília, da qual resultaram tais informações, contudo, ficaram pendentes de resposta até o momento da publicação dados sobre o número de estudantes admitidos, os cursos e os anos de ingresso. Agradecemos o retorno da Assessoria de Assuntos Internacionais (INT/UNB), que encaminhou pedido às secretarias de cursos, responsáveis pelas estatísticas quanto aos discentes admitidos.

${ }^{23}$ Resolução no 66/2010/UFES.

${ }^{24}$ Menção ao Ofício no 3.660/95 da Secretaria de Educação Superior do Ministério da Educação e Desporto (SESu/MEC).

${ }^{25}$ Segundo informações da Pró-Reitoria de Ensino da UFTM.

${ }^{26}$ Resolução 17/2003 - CONSU, de 04 de setembro de 2003, regulamentada pela Resolução 005/2004
} 
ociosas $^{27}$. Para a inscrição no programa, além da comprovação da condição de refugiado, é necessária comprovação de documentação que ateste a conclusão do Ensino Médio ou atestado emitido pelo CONARE, com tradução simples, podendo elencar até três opções de inscrição de cursos, que serão avaliados pelas coordenações. O processo seletivo prevê a realização de prova de língua portuguesa e de conhecimentos específicos conforme o curso pretendido além de entrevista pessoal, ainda que o número de inscritos seja inferior ao número de vagas $^{28}$. Não estão previstas nas resoluções políticas de permanência vinculadas a bolsas, moradia ou auxílios. Apesar das normas referirem expressamente à admissão apenas de refugiados políticos, guia acadêmico elaborado pela universidade refere os artigos da Lei 9.474/97 como base para a admissão (UFJF, 2012), portanto, depreende-se que são admitidos estudantes com situação de acordo com as causas de refúgio elencadas pelo Estatuto do Refugiado, já dentro da definição ampliada conforme a Declaração de Cartagena de 1984.

Também em Minas Gerais, o programa da Universidade Federal do Triângulo Mineiro (UFTM) foi criado em 2016 e contou com um edital ${ }^{29}$ de 36 vagas para ingresso em 2017 em diversos cursos de graduação destinados a refugiados reconhecidos pelos CONARE. O edital dispunha que o processo seletivo simplificado seria realizado através de prova de redação em língua portuguesa, com admissão de inscrição mediante comprovação de escolaridade do país de origem ou de declaração do CONARE, como preconiza a Lei 9474/97. O concurso teve nove inscritos, quatro aprovados e três matriculados, e a falta de divulgação é apontada como um fator que prejudica o preenchimento de vagas. Dentre os aprovados, dois alunos falam árabe, o que tem demandado adaptações como a oferta de aulas de português e reforço para sua permanência. $\mathrm{O}$ acesso à assistência estudantil é ofertado, contudo, é visto como um problema tendo em vista o baixo valor da bolsa de assistência estudantil. Apesar de não constarem diretrizes sobre a regularidade do programa nas normativas, a UFJF está preparando novo edital para ingresso em $2018^{30}$.

\subsection{Programas implementados com acesso a refugiados, solicitantes de refúgio e portadores de visto humanitário: UEG, UFSM e UFPR}

\footnotetext{
${ }^{27}$ Segundo Art. $3^{\text {o }}$, § único, Resolução 005/2004, que estabelece que as vagas poderão ser criadas ainda que não existam vagas ociosas.

${ }^{28}$ Não foram localizados os editais com a descrição dos procedimentos nem informações acerca de quantos já foram realizados, sendo as informações apenas as referentes ao artigo $5^{\circ}, \S 1^{\circ}$, resolução 005/2004.

${ }^{29}$ Foram publicados dois editais para o mesmo processo seletivo, o primeiro, em dezembro de 2016 (Edital $n^{\circ}$ 11/2016/DPSD/UFTM de 15 de setembro de 2016 e o segundo edital complementar $n^{\circ}$ 18/2016/DPSD/UFTM de 23/7/2016.

${ }^{30}$ Agradecemos as informações prestadas pela Pró-Reitoria de Ensino da UFTM.
} 
O Brasil tem recebido um número cada vez maior de migrantes, solicitantes de refúgio e refugiados, além dos portadores de visto humanitário, concedido primeiramente a haitianos e posteriormente também a sírios para ingresso no Brasil, com a diferença de que esses últimos, ao ingressarem, tiveram a possibilidade de serem reconhecidos como refugiados. Os haitianos que chegaram ao Brasil a partir de 2012 não foram considerados refugiados, apesar das discussões acadêmicas sobre a presença militar brasileira no Haiti e o conceito de refúgio ambiental (CLARO, 2012). Assim, a concessão do visto permanente por razões humanitárias ${ }^{31}$, colocou haitianos sob a tutela da legislação geral sobre imigrantes, criando um status jurídico à parte, mas vinculado à Lei 6.815/80. Dados do Sistema Nacional de Cadastro e Registro de Estrangeiros (SINCRE) da Polícia Federal, indicam que as cinco nacionalidades de maior presença no Brasil entre 2000 a 2015 foram bolivianos, estadunidenses, argentinos, chineses e portugueses, respectivamente (DA COSTA, 2016). Todos esses "estão" na categoria de imigrantes. Já os dados do CONARE apontam um grande contingente de solicitantes de refúgio do Senegal, Nigéria e Gana acumulados até 2016 (CONARE, 2016), além da prevalência de refugiados reconhecidos da Síria, República Democrática do Congo e Angola.

Com exceção dos tradicionais fluxos migratórios norte-sul ilustrados nas estatísticas, temos que os dados disponibilizados por esses órgãos têm um fator em comum: a predominância dos deslocamentos sul-sul em primeira posição em todos os grupos. Em sua maioria indígenas latino-americanos ou de origem caribenha e africana, os cidadãos mais vulneráveis dentre essas categorias jurídicas apenas teriam meios de acesso ao ensino superior em posição de igualdade com todos os brasileiros, por não estarem vinculados a categoria jurídica de refugiados. Em situações de violência bastante semelhantes aos refugiados reconhecidos, frequentemente não possuem formas de comprovar sua escolaridade, por terem partido de seus países motivados por situações de violência, "crises" humanitárias e desastres ambientais. Com frequência também possuem condições sócio-econômicas frágeis, tanto pelos riscos a que foram expostos durante o seu deslocamento e chegada no Brasil, como a mediação de coyotes e as dinâmicas de tráfico de pessoas, quanto pela sua dificuldade de inserção no país com a documentação e as estruturas de acolhimento disponíveis. Se considerarmos esses elementos, muitas pessoas nessas situações possuem poucas condições de obter êxito em processos seletivos pelas vias usuais, como vestibulares ou pelo Exame

\footnotetext{
${ }^{31}$ Regulado pela Resolução Normativa $n^{\circ} 97$ do Conselho Nacional de Imigração (CNIg), órgão veiculado ao Ministério do Trabalho e Emprego (MTE).
} 
Nacional do Ensino Médio, tanto pelo custo inerente a esses concursos e pelo desconhecimento do sistema de ensino brasileiro, quanto pelo domínio da língua portuguesa.

Nesse sentido, se considerarmos que o sistema de refúgio se estrutura por um caráter positivista, dado que categoria "refugiado" foi despolitizada e construída mediante discursos de neutralidade e universalidade, estabelecendo uma divisão entre as esferas legal e política dos sistemas de refúgio como um todo (CHIMNI, 1998), temos que os migrantes possuiam um sistema protetivo mais frágil do que os refugiados reconhecidos, tanto por estarem tutelados pelo Estatuto do Estrangeiro, quanto por critérios sócio-econômicos e também étnico-raciais que predominam nesses grupos. A condição de muitos migrantes e solicitantes quanto ao acesso a direitos é, portanto, mais difícil, por estarem previstas menos garantias legais, situação que poderá ser modificada com a entrada em vigência da nova lei, conforme constatado na pesquisa conduzida pelo Ministério da Justiça em parceria com o IPEA em todo país (MINISTÉRIO DA JUSTIÇA, 2015:33):

\begin{abstract}
Constatou-se que o Brasil, por meio de seus marcos jurídicos e institucionais e de suas políticas migratórias e de direitos humanos, não atende boa parte das recomendações e diretrizes internacionais em matéria de direitos humanos dos imigrantes e acesso a serviços. Requer-se, assim, uma adequação da política migratória brasileira às exigências internacionais, notadamente pela incorporação da dimensão dos direitos humanos na política migratória e da dimensão migratória nas políticas públicas e programas sociais em matéria de direitos, como saúde, educação, moradia, dentre outros. A política migratória brasileira deve adotar uma abordagem pautada nos direitos humanos e uma perspectiva de gênero, dentre outras medidas, para atender às necessidades especiais dos imigrantes, notadamente os grupos vulneráveis.
\end{abstract}

Por essa razão, justifica-se que alguns programas adotem critérios de adesão à portadores de visto humanitário e solicitantes de refúgio, por compreender que o seu acesso ao ensino superior é dificultado. Outro elemento norteador foi a situação vivenciada em determinadas regiões do Brasil com a concentração de grupos de migrantes com as características de vulnerabilidade mencionadas, sendo essa uma justificativa de instauração dos programas. Tais aspectos foram favorecidos em três universidades em diferentes regiões do Brasil com programas implementados: a Universidade Estadual de Goiás (GO), na região Centro-Oeste, a Universidade Federal de São Carlos (SP), no Sudeste, e a Universidade Federal de Santa Maria (RS), no sul. A inclusão de solicitantes de refúgio também tem sido adotada por outros programas em implementação, como o da Universidade Federal do ABC (SP), criado em 2017, sendo sugerida a ampliação também na UFMG (MG), como já mencionado. 
O programa da UEG foi criado em $2015^{32}$ com a previsão de vagas em cursos técnicos, de formação continuada e de uma vaga suplementar em cada curso de graduação, assim como acesso às vagas ociosas da universidade e vagas nos cursos do Pronatec, com prioridade. Na justificativa do programa, constam "o esforço brasileiro para apoiar a reconstrução do Haiti e em abrigar cidadãos do oriente médio e a comunidade de cidadãos refugiados existente na região de abrangência da UEG", além do compromisso da universidade com os direitos humanos e a concessão de vistos humanitários pelo Conselho Nacional de Imigração (CNIg) a cidadãos de países em situação de conflito sócioeconômico $^{33}$. A oferta de vagas será avaliada anualmente, e o processo seletivo especial já está na segunda edição. O primeiro edital, para início em $2017^{34}$, previa um total de 138 vagas dentre os 41 campi da universidade e em diversos cursos de graduação. A inscrição foi admitida somente na modalidade presencial, com apresentação de documentos, dentre eles a comprovação de escolaridade, que poderia ser emitida por declaração do CONARE ou declaração a próprio punho. No ato da inscrição, era possível optar por dois cursos de graduação, e a seleção foi realizada através de prova com quarenta questões objetivas, incluindo a opção por prova de língua estrangeira e também redação ${ }^{35}$, em caráter eliminatório e classificatório. O edital para entrada em $2018^{36}$ prevê, igualmente, 140 vagas para ingresso em todos os campi, mantidas as demais condições de inscrição e modelo de avaliação para ingresso.

No mesmo sentido, mas visando contemplar portadores de visto humanitário, o programa da Universidade Federal de Santa Maria (UFSM) foi criado em 2016, desenvolvido a partir de resolução de $2010^{37}$, que embora previsse o acesso, tornava-se inacessível pelo grande número de documentos exigidos e apenas admitia discentes refugiados. $\mathrm{O}$ caso da UFSM merece destaque por disponibilizar vagas em cursos técnicos, tecnólogos e de graduação $^{38}$, com processo seletivo especial de apresentação de documentos de comprovação de escolaridade ou resultados do ENEM, e previsão de criação de 5\% de vagas novas ou uso de vagas remanescentes. O primeiro edital, com início em 2016, teve 26 inscritos e admitiu casos de pessoas sem diploma no país de origem, com formação inconclusa ou diploma não

\footnotetext{
${ }^{32}$ O programa foi criado pela resolução CSUN no 739 de 3 de dezembro de 2015.

${ }^{33}$ Preâmbulo da Resolução CSU no 34, renumerada como Resolução CsUN 739, de 2015.

${ }^{34}$ Edital $n^{\circ} 1$ de 6 de outubro de 2016.

${ }^{35}$ Foram também previstas provas de conhecimentos específicos para os cursos de arquitetura e apresentação de atestado médico para o curso de educação física.

${ }^{36}$ Edital $\mathrm{n}^{\mathrm{o}} 1$, de 13 de setembro de 2017.

${ }^{37}$ Res. 39/2010, de 13 de dezembro de 2010, UFSM

${ }^{38}$ Regido pela Resolução 41/2016 UFSM.
} 
revalidado. O programa foi motivado pelo trabalho de pesquisa de campo em que foi constatada grande demanda de acesso ao ensino superior por migrantes no Rio Grande do Sul, sobretudo haitianos e senegaleses, do qual pude participar e documentar (ROSSA, 2017).

Também na região sul está situado o programa da Universidade Federal do Paraná (UFPR), que apesar de constar na análise como um processo seletivo, tem dinâmica mais próxima a um programa de reingresso ou transferência. $\mathrm{O}$ acesso à refugiados na UFPR teve início em 2014 para refugiados e portadores de visto humanitário ${ }^{39}$, contudo, os candidatos inscritos precisam ter iniciado curso de graduação em seu país de origem, e optar pela mesma modalidade de graduação. O programa prevê a distribuição de vagas remanescentes ${ }^{40}$ dentre as resultantes de evasão nos cursos de graduação, com a realização de equivalência do histórico acadêmico, caso a caso. Não está previsto processo seletivo, salvo nos casos em que não for possível a apresentação de histórico, sendo admitida declaração do CONARE, situação na qual estão previstas a realização de provas de equivalência em português ou inglês, além de um plano de estudos. Já foram realizados dois editais, em 2015 e 2016, com um total de 38 vagas ofertadas. O programa tem iniciativas inovadoras, como a previsão de um professor tutor e estudantes instrutores durante o período de adaptação no curso e a inclusão dos discentes em curso de língua portuguesa em núcleo de extensão da universidade $^{41}$. No edital de 2015, 14 dos 24 ingressantes receberam bolsas de permanência com auxílio moradia, vale-transporte e acesso ao refeitório universitário (ANDIFES, 2016) e participaram de curso de idiomas e em 2017, foram ofertadas 14 vagas em diversos cursos. As inscrições para as edições anteriores foram realizadas pessoalmente, mediante formulários bilíngües disponibilizados em espanhol, francês e inglês, sendo admitido também o protocolo de inscrição mediante procuração. O curso foi motivado pela solicitação de uma estudante síria $^{42}$ que em 2017 concluiu a graduação em arquitetura e foi a primeira formanda do programa. As atividades da CSVM/UFPR prevêem também auxílio em processos de revalidação de diploma de refugiados e portadores de visto humanitário já graduados ${ }^{43}$, inclusive com a possibilidade de isenção de taxa de revalidação.

\footnotetext{
${ }^{39}$ Resolução CEPE-UFPR n ${ }^{\text {o }}$ 13/14

${ }^{40}$ Vinculado ao Programa de Ocupação de Vagas Remanescentes (Provar), UFPR.

${ }^{41}$ Disposições previstas nos artigos $8^{\circ}, \S 2^{\circ}$ e 10 da Resolução 13/14 CEPE/UFPR.

${ }^{42} \mathrm{O}$ caso de uma estudante de arquitetura síria é relatado em reportagem da universidade, disponível em: <http://www.ufpr.br/portalufpr/blog/noticias/jovem-siria-ingressa-na-ufpr-na-condicao-de-refugiada-de-guerra/>

${ }^{43}$ EDITAL n 32/2017 - Revalidação/NC-PROGRAD/UFPR
} 


\subsection{Programas com processos seletivos por critério de nacionalidade: UNILA e UFFS ${ }^{44}$}

Além dessas iniciativas, outras duas universidades implementaram ações específicas para portadores de visto humanitário, com menção expressa a haitianos, resgatando um programa pré-existente, o PROHAITI. O programa original do ProHaiti foi criado pela CAPES em 2010 e já vinha sido implementado, desde 2011, em quatro universidades brasileiras $^{45}$ : UNICAMP, UFRGS, UFSCAR e UFSC. Concebido como uma mobilidade de intercâmbio estudantil com bolsa de estudos, aos moldes dos já existentes PEC-G e PEC-PG ${ }^{46}$, convênios de cooperação com países em desenvolvimento, o programa teve 61 participantes, dos quais 27 são discentes e 34 já estão graduados (ALPHONSE, MACEDO,2016). Selecionamos os casos da UNILA E UFFS por representarem uma alteração original no programa, que passou a receber inscritos já residentes no Brasil, além de retirar a exigência do início da graduação no país de origem.

O programa da UNILA foi iniciado em $2014^{47}$ com o intuito de promover a integração de imigrantes haitianos no Brasil, considerando especialmente o racismo e xenofobia a que são expostos no estado do Paraná (UNILA,2014). Foram realizadas duas seleções, em 2014 e 2015, sendo previstas 29 vagas no primeiro edital e 10 vagas no segundo, com vinculação ao acesso de assistência estudantil integral por toda a duração do curso, sem a cobrança de taxas e sem a realização de provas. Ambos editais da UNILA previram como requisito que os candidatos fossem haitianos ${ }^{48}$ residentes no Brasil, não possuíssem diploma de ensino superior e fossem portadores de visto permanente em caráter humanitário, o que torna esse tipo de seleção vinculado à nacionalidade e não apenas à condição migratória.

Já o programa da UFFS foi criado em $2013^{49}$ considerando a comunidade de haitianos existente nas suas regiões de abrangência, em especial do Campus Chapecó ${ }^{50}$. O programa da UFFS prevê que a oferta de vagas será avaliada anualmente conforme estudos

\footnotetext{
${ }^{44}$ As reflexões dessa unidade foram desenvolvidas a partir de pesquisa e as contribuições realizadas durante apresentação de trabalho apresentado no Seminário Internacional Epistemologias do Sul, em julho de 2017, na Universidade Federal da Integração Latino-Americana (UNILA). O resumo expandido referente ao trabalho aguarda publicação.

${ }^{45}$ O Pró-Haiti é regulamentado pela Portaria Nº92/2010 da CAPES e prevê modalidades de cooperação em formação de recursos humanos e reestruturação de ensino superior no Haiti, sendo a primeira modalidade prevista como mobilidade acadêmica com bolsas de graduação sanduíche de estudantes haitianos que cursassem ensino superior no Haiti, os quais viriam estudar no Brasil.

${ }^{46}$ O PEC-G, Programa de Estudantes-Convênio de Graduação, foi criado em 1965 e o PEC-PG, Programa Estudante Convênio de Pós-Graduação, foi criado em 1981. Ambos os programas são atualmente voltados para estudantes de países em cooperação sul-sul da América Latina e Caribe, África e Ásia.

${ }^{47}$ O programa é regulamentado pela Resolução CONSUN nº 037/14 UNILA.

${ }^{48}$ Ambos editais não admitem cidadãos binacionais ou com um dos genitores brasileiros.

${ }^{49}$ Regulamentado pela Resolução CONSUNI n ${ }^{\circ}$ 032/2013 UFFS.

${ }^{50}$ Conforme consta no preâmbulo da Resolução CONSUNI n ${ }^{\circ}$ 032/2013 UFFS.
} 
sobre a população de haitianos nos municípios de abrangência da Universidade e a ocupação de vagas ofertadas no processo seletivo regular, o que implica em um caráter suplementar, como na UNILA. O processo da UFFS não prevê a garantia à assistência estudantil, contudo, segundo Bordignon e Piovezan (2015), tem sido oferecidas políticas de permanência e assistência como auxílio alimentação, moradia, transporte e material didático, o que age como um respaldo contra a evasão acadêmica.

\section{Considerações finais}

A importância do acesso ao ensino superior na integração de migrantes e refugiados, o aumento do número de solicitações de refúgio e a concessão de vistos humanitários no Brasil e recentes discussões sobre o acesso a direitos e políticas públicas para a população migrante, culminando na aprovação da Nova Lei de Migração, apontam a atualidade do tema de acesso à educação. A integração dessa demanda não apenas como uma agenda de pesquisa no ensino superior, conduzida sobretudo através da instauração das Cátedras Sérgio Vieira de Melo, mas também como um tema importante na agenda migrante de acesso a direitos desponta como elemento convergente.

Ainda que o desenho dos programas tenha sido conduzido de forma diferente por cada instituição, temos linhas gerais seguidas por cada uma das iniciativas e nessa análise preliminar dos programas de acesso ao ensino superior para migrantes e refugiados, criados e implementados até a atualidade, pudemos observar algumas tendências. Primeiramente, é importante pontuar que nenhum dos programas avaliados cobrou taxa de inscrição, contudo, observamos diferentes formas de exigência de documentação assim como a realização de inscrição presencial, o que pode reduzir o acesso de alguns candidatos. Iniciativas como a realização de inscrição on-line, recebimento de inscrição por procuração e a disponibilização de formulários bilíngues são boas práticas que poderiam ser adotados em mais universidades. Ademais, a exigência de documentos traduzidos por tradutor juramentado, flexibilizada em alguns casos, e a aceitação de declarações de escolaridade emitidas pelo CONARE pela totalidade dos programas parece apontar para uma sensibilidade administrativa por parte dos gestores, considerando a situação especial de refugiados e migrantes preconizada pela própria Lei 9474/97. A falta de divulgação sobre os programas tem sido descrita como uma das dificuldades para o preenchimento das vagas, assim como em alguns casos foi possível observar que o número de aprovados foi inferior ao número de vagas ofertadas. Tais aspectos podem indicar que é necessário ajustar as formas de acesso, contemplando processos seletivos 
que levem em conta a situação dos migrantes que estejam há menos tempo no país, numa realidade em que grande parte das pessoas detentoras da condição de refúgio e de vistos humanitários tem fixado residência no Brasil há menos de uma década. Um elemento que assinalamos como importante é o destaque dado por alguns programas para processos seletivos que tenham a língua como critério eliminatório, sendo um caminho que as próprias universidades e Cátedras invistam no potencial de projetos extensionistas de ensino de português como língua estrangeira e motivem a inclusão de migrantes em cursinhos populares, de forma a integrá-los efetivamente nos programas de acesso.

Quanto a distribuição geográfica dos programas e a divisão de análise aqui proposta por status jurídicos, temos algumas observações. Se, por um lado, observamos programas orientados apenas para o acesso de refugiados em sentido estrito (UFSCAR, UFMG, UNB, UFES, UFJF e UFTM), o que limita o acesso a solicitantes de refúgio e portadores de visto humanitário, temos que é necessário uma análise aprofundada para verifica o porquê de não inclusão de outros status jurídicos nesses programas mesmo quando as vagas não forem preenchidas. A realidade brasileira atual, em que o decurso de tempo entre a solicitação de refúgio e o deferimento do pedido podem levar, em média, 2 anos, aponta para os desafios contidos na vinculação entre o status jurídico e o acesso à educação superior.

Em relação ao segundo grupo de instituições (UEG, UFPR, UFSM, UFFS, UNILA, e futuramente, UFABC) que inclui aos programas de acesso outros status jurídicos, como os solicitantes de refúgio em situação de vulnerabilidade social e econômica e portadores de visto humanitário, temos dentre os casos analisados diferentes critérios de admissibilidade que tendem a refletir e reforçar critérios de distribuição espacial distintos. Compreendemos que a predominância de programas que viabilizam acesso a portadores de visto humanitário e cidadãos haitianos na região sul, programas esses criados após 2014, implica em uma preocupação com fatores sócio-econômicos e ambientais como motivadores de deslocamentos forçados, estando mais sintonizados com a discussão sobre migrações na atualidade, que transcendem os critérios de proteção restritos ao sistema de refúgio. Um elemento que parece ter sido importante na criação desses programas é a prevalência de migrantes haitianos na região sul do Brasil, o que tem sido apontado demograficamente e parece ter precedido a criação dos programas, ainda que a continuidade de chegada dos migrantes também possa ser um elemento que tenha motivado a sua criação.

É possível supor que a distribuição de acesso ao ensino superior crie um efeito de migração interna entre migrantes internacionais, com alguns casos já relatados pela imprensa (TOLEDO, 2017; BAZZO, FAJARDO, 2017) embora a dificuldade na permanência e 
participação dos programas pelo critério geográfico tenha sido apontada, também demonstrado na relação entre o menor preenchimento de vagas e a realização de programas inscrições e processos seletivos presenciais. Ainda que tenha sido conduzido um estudo quantitativo sobre o acesso ao ensino superior público, é importante ressaltar que outros critérios tendem a influenciar na adaptação, permanência e evasão, e portanto sucesso dos programas, como disponibilidade de bolsas e apoio sócio econômico, infra-estrutura da universidade com apoio à integração cultural e linguística, existência de convênios nas universidades com intercâmbio de estudantes internacionais e nível de integração da universidade com a comunidade local. Assim, o presente estudo, que se propõe a ser um levantamento inicial da distribuição de acesso ao ensino superior público no Brasil para imigrantes e refugiados, demanda um maior aprofundamento e pesquisa qualitativa para avaliar a efetividade, continuidade e eventualmente, expansão desses modelos em outras universidades e regiões brasileiras.

\section{Referências Bibliográficas}

ACNUR, Alto Comissariado das Nações Unidas para Refugiados. Refúgio no Brasil: uma analise estatística (2010-2013). 2014. Disponível em: < http://www.acnur.org/t3/fileadmin/Documentos/portugues/Estatisticas/Refugio_no_Brasil_20 10_2013.pdf >. Acesso em: 30 set. 2017.

ALPHONSE, Fritznel, MACEDO, José Rivair. Análise do programa Pró-haiti implementado nas universidades públicas brasileiras como a unicamp, ufsc, ufscar e ufrgs nos anos de 2011 a 2016. No prelo, 2016.

ANDIFES, Associação Nacional dos Dirigentes das Instituições Federais de Ensino Superior. Universidade Federal do Paraná recebe refugiados que interromperam estudos em seus países de origem. 19 mai. 2016. Disponível em: <http://www.andifes.org.br/universidade-federal-do-parana-recebe-refugiados-queinterromperam-estudos-em-seus-paises-de-origem/>. Acesso em: 10 jun. 2017.

BAENINGER, Rosana. Migração internacional: elementos teóricos para o debate. In: Imigração Haitiana no Brasil. Baeninger; Peres; Fernandes et al (Org.) Jundiaí: Paco Editorial, 2017.

BORDIGNON, Sandra de A. F; PIOVEZAN, Leonel. Práticas de integração na diversidade: das intenções à criação do Prohaiti na UFFS. In: Anais do XII Educere, Formação de Professores, complexidade e trabalho docente. Curitiba, 29 a 29 de 2015, p. 928 944.

BAZZO, Gabriela, FAJARDO, Vanessa. Universidades brasileiras matricularam cerca de 70 refugiados em menos de um ano, diz Acnur. G1, 21 set. 2017. Disponível em: 
<https://g1.globo.com/educacao/noticia/universidades-brasileiras-matricularam-cerca-de-70refugiados-em-2016-diz-acnur.ghtml>. Acesso em: 25 set. 2017.

DA COSTA, Nayara Belle Nova. Migrações Internacionais e Refúgio no Brasil entre 2000 e 2014: uma análise espaço-temporal. Dissertação de Mestrado. Departamento de geografia, Universidade de Brasília. Brasília: 2016.

CHIMNI, B. S. The Geo-Politics of Refugee Studies: A view from the south. Journal of Refugee Studies, 11 (4), 1998, p.350-374.

CLARO, Carolina. Refugiados Ambientais: mudanças climáticas, migrações internacionais e governança global. Dissertação de Mestrado, Centro de Desenvolvimento Sustentável, Universidade de Brasília, 2012.

CONARE, Comitê Nacional para Refugiados. Sistema de Refúgio brasileiro: Desafios e perspectivas. Relatório de gestão, disponível em: < http://www.acnur.org/t3/fileadmin/Documentos/portugues/Estatisticas/Sistema_de_Refugio_b rasileiro_-_Refugio_em_numeros_-_05_05_2016.pdf>. Acesso em: 5 set. 2017.

MAZZA, Débora; NORÕES, Katia.(Orgs). Educação e migrações internas e internacionais- Um diálogo necessário. Jundiaí, Paco Editorial, 2016.

MINISTÉRIO DA JUSTIÇA. Migrantes, Apátridas e Refugiados: subsídios para o aperfeiçoamento de serviços, direitos e políticas públicas no Brasil. Ministério da Justiça, Secretaria de Assuntos Legislativos. Brasília: Série Pensando o Direito, IPEA, 2015.

MAGALHÃES, Giovana Modé; WALDMAN, Tatiana Chang. A educação escolar de refugiados e solicitantes de refúgio: um olhar exploratório sobre a cidade de São Paulo. In: MAZZA, Débora; NORÕES, Katia.(Orgs). Educação e migrações internas e internacionais- Um diálogo necessário. Jundiaí, Paco Editorial, 2016.

MARINO, Aline Marques. Pró-haiti: reflexões sobre as ações afirmativas para haitianos nas universidades públicas brasileiras. XXV Encontro nacional do Conpedi Brasília/DF,2016.

NEVES, Thalita. Refugiados são tema de reunião. NEPPE- Núcleo de Ensino e Pesquisa em Português para Estrangeiros. Disponível em: <http://www.neppe.unb.br/br/index.php/br/news/105-refugiados-sao-tema-de-reuniao-entreunb-e-onu>. Acesso em: 10 set. 2017.

RODRIGUES, Gilberto M. A. ACNUR e Universidades: a Cátedra Sergio Vieira de Mello (CSVM) no Brasil In: Cadernos de Debates Refúgio, Migrações e Cidadania, v.9, n.9 , 2014. Brasília: Instituto Migrações e Direitos Humanos, IMDH. 
ROSSA, Lya Amanda. Dificuldades e oportunidades: um breve relato dos extremos vividos por migrantes no Sul do Brasil. Migramundo, 15 mar. 2017. Disponível em: <http://migramundo.com/dificuldades-e-oportunidades-um-breve-relato-dos-extremosvividos-por-migrantes-no-sul-do-brasil/>. Acesso em: 5 jun. 2017.

TOLEDO, Luiz Fernando. Cresce $\mathbf{n}^{\mathbf{0}}$ de universidades brasileiras que acolhem refugiados. Estado de São Paulo, 11 set. 2017. Disponível em: $<$ http://educacao.estadao.com.br/noticias/geral,cresce-n-de-universidades-brasileiras-queacolhem-refugiados,70001984155>. Acesso em: 15 set. 2017.

UFJF, Universidade Federal de Juiz de Fora. Guia da Central de Atendimento da UFJF. 16 out. 2012. Disponível em:

<http://www.ufjf.br/ecogv/files/2015/12/Guia-da-Central-de-Atendimento-da-UFJF-1.3.pdf>. Acesso em: 2 set. 2017.

Universidade abre inscrições em cursos de graduação para refugiados políticos. 19 mai. 2016.2 Disponível em: <http://www.ufjf.br/noticias/2016/05/19/universidade-abre-inscricoes-em-cursos-degraduacao-para-refugiados-politicos/>. Acesso em: 8 set. 2017.

Resolução $\mathbf{n}^{\mathbf{0}}$ 17, 04 setembro de 2003. Dispõe sobre o ingresso de Refugiados Políticos nos Cursos de Graduação da UFJF. Disponível em: <http://www.ufjf.br/portal/files/2009/06/resolucao17.pdf>.Acesso em: 8 set. 2017.

UFSCAR, Universidade Federal de São Carlos. Relatório de gestão 2012-2016 . PróReitoria de Graduação, Outubro de 2016. Disponível em: <http://www.blogdareitoria.ufscar.br/wp-content/uploads/rt_prograd.pdf>. Acesso em: 5 jun. 2017.

Política de ações afirmativas, diversidade e equidade da Universidade Federal de São Carlos. São Carlos: UFSCar, 2016b. Disponível em: <http://www.nepedeees.ufscar.br/arquivos/politica-de-acoes-afirmativas-diversidade-eequidade-da-ufscar>. Acesso em: 5 jun. 2017.

UNILA, Universidade da Integração Latino-Americana. Programa da UNILA oferece vagas para imigrantes haitianos em 29 cursos. Disponível em:< https://www.unila.edu.br/noticias/pro-haiti>. Acesso em: 5 jun. 2017.

WALDMAN, Tatiana Chang. O acesso à educação escolar de imigrantes em São Paulo: A trajetória de um direito, 238p.. Dissertação de Mestrado. Faculdade de Direito, Mestrado em Direitos Humanos, Universidade de São Paulo, 2012. 